\title{
Identification of stakeholder perspectives on future flood management in the Rhine basin using $Q$ methodology
}

\author{
G. T. Raadgever, E. Mostert, and N. C. van de Giesen \\ Water Resources Management, Delft University of Technology, P.O. Box 5048, 2600 GA Delft, The Netherlands
}

Received: 17 January 2008 - Published in Hydrol. Earth Syst. Sci. Discuss.: 18 February 2008

Revised: 23 May 2008 - Accepted: 25 June 2008 - Published: 12 August 2008

\begin{abstract}
This article identifies different stakeholder perspectives on future flood management in the downstream parts of the Rhine basin in Germany and The Netherlands. The perspectives were identified using Q methodology, which proved to be a good, but time-intensive, method for eliciting and analyzing stakeholder perspectives in a structured and unbiased way. Three shared perspectives were found: A) "Anticipation and institutions", B) "Space for flooding" and C) "Knowledge and engineering". These three perspectives share a central concern for the provision of safety against flooding, but disagree on the expected autonomous developments and the preferred measures. In perspective $\mathrm{A}$, the expected climate change and economic growth call for fast action. To deal with the increasing flood risk, mostly institutional measures are proposed, such as the development of a stronger basin commission. In perspective $\mathrm{B}$, an increasing spatial pressure on the river area is expected, and the proposed measures are focused on mitigating damage, e.g., through controlled flooding and compartmentalization. In perspective $\mathrm{C}$, the role of expert knowledge and technological improvements is emphasized. Preferred strategies include strengthening the dikes and differentiation of safety standards.

An overview of stakeholder perspectives can be useful in natural resources management for 1) setting the research agenda, 2) identifying differences in values and interests that need to be discussed, 3) creating awareness among a broad range of stakeholders, and 4) developing scenarios.
\end{abstract}

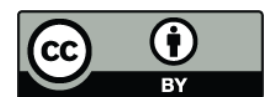

Correspondence to: G. T. Raadgever (g.t.raadgever@tudelft.nl)

\section{Introduction}

Many water management issues are characterized by limited technical knowledge and disagreement about the goals to achieve. Finding "the right solutions for the right problems" then requires that the stakeholder reach agreement on the goals, or at least on the measures to be taken, and that missing technical knowledge is produced. The first step towards that end is to elicit the different stakeholder perspectives.

A stakeholder perspective is the cognitive representation that a stakeholder makes of the external reality and his or her position in this reality. It includes the stakeholder's preferences concerning management options, as well as the values, specific interests, and knowledge that underlie these preferences (cf. the concepts "mental model" in Doyle and Ford, 1998; Kolkman et al., 2005; and "(issue) frame" in Dewulf et al., 2004). Developing an overview of the different stakeholder perspectives can increase awareness of other perspectives, facilitate discussion and support critical reflection on the rationality behind stated positions. This may result in better mutual understanding and consensus between stakeholders (Pahl-Wostl and Hare, 2004; Ridder et al., 2005).

The main purpose of this article is to present the different stakeholder perspectives on future flood management in the Rhine. These perspectives were elicited as part of an ongoing scenario study, in which researchers, policymakers, and other stakeholders from Germany and The Netherlands jointly explore long-term flood management strategies in the Rhine basin. The study was initiated by the research projects ACER (http://ivm5.ivm.vu.nl/adaptation/project/acer) and NeWater (http://www.newater.info), in collaboration with the GermanDutch Working Group on Flood Management (WGFM). The aim of the study is to promote the exchange of perspectives and expert knowledge, and to support the development of a shared vision on flood management until 2050. To

Published by Copernicus Publications on behalf of the European Geosciences Union. 


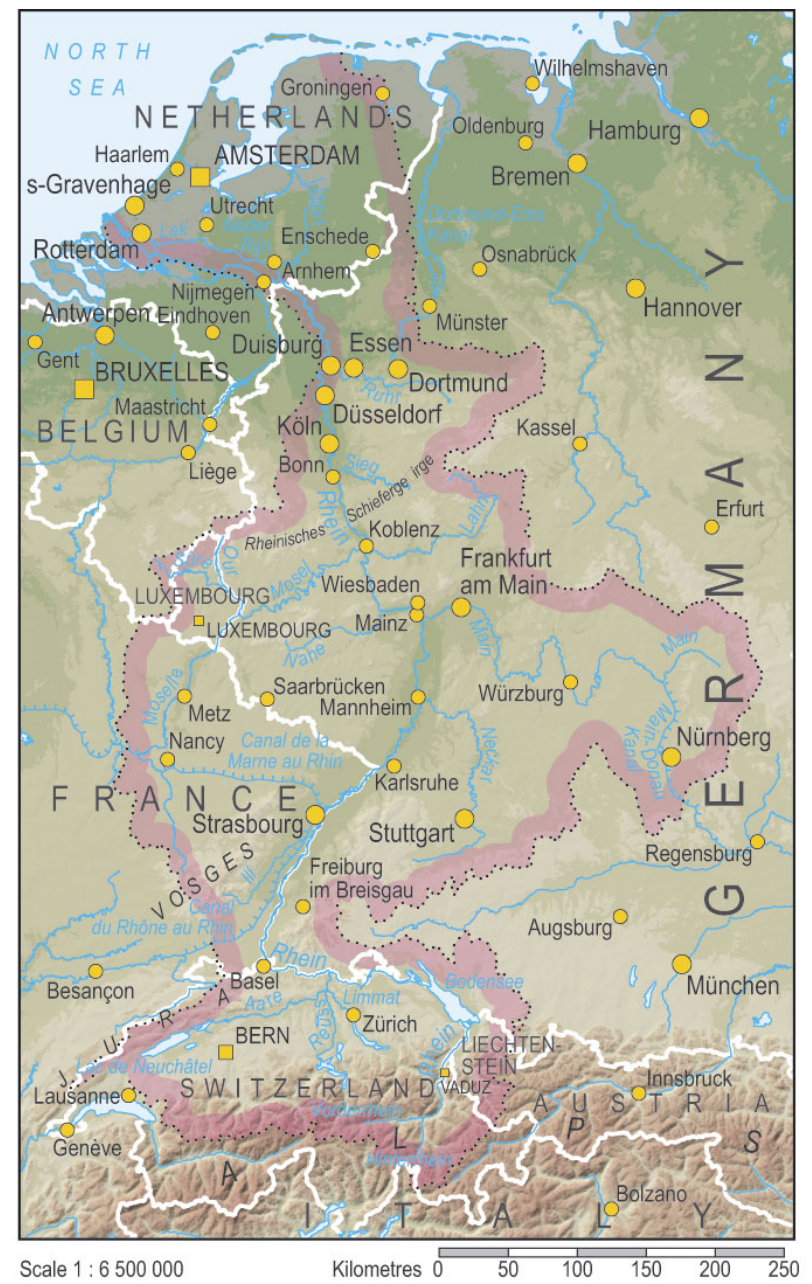

Fig. 1. Map of the Rhine basin (UNEP/DEWA/GRIDEurope, Retrieved 22-08-07 from http://www.grid.unep.ch/product/ publication/freshwater_europe/images/map4.jpg).

this end, four stakeholder workshops are organized to identify relevant external developments, the desired future situation, and management strategies to bring the desired situation closer. In-between the workshops, the outcomes of different strategies under different scenarios are assessed, using atmospheric, hydrological, hydrodynamic, and damage modeling. As input for the study, an overview of stakeholder perspectives was made in order to develop awareness among the stakeholders of others' perspectives, and to stimulate discussion. Existing studies either cover only the topic of climate change, or exclusively use scenarios based on cultural theory (Thompson et al., 1990) to study future flood management in the Rhine basin (e.g., van Asselt et al., 2001). They do not use the perspectives of flood management stakeholders.

Secondary purposes of this article are to show how stakeholder perspectives can be measured and analyzed, and how perspectives can be used to deal with complex natural resources management issues. The literature indicates that $\mathrm{Q}$ methodology is a good methodology for eliciting and analyzing perspectives, and presents several applications in the field of environmental management (e.g., Steelman and Maguire, 1999). Three applications in the field of water management could be found, concerning: 1) aesthetics of the waterfront of the Nile in Cairo (Gabr, 2004), 2) the public participation process in ten cases of environmental decision making (Webler and Tuler, 2006), and 3) economic activities and management preferences in the Illinois River basin (Focht, 2002).

This article first introduces current flood management in the Lower Rhine basin. Next, it describes Q methodology and how it was applied in the case study. The core of the article is formed by Sects. 4 and 5, which present and analyze the perspectives that were identified. Section 6 describes how perspectives have been - and can be - used in natural resources management. Finally, Sect. 7 presents the main conclusions.

\section{Flood management in the Lower Rhine basin}

The Rhine is a large river with a basin of almost $200000 \mathrm{~km}^{2}$ that is shared by nine European countries (see Fig. 1). Originating in the Swiss Alps, the river runs through Germany and The Netherlands into the North Sea. The Rhine river has a combined rainfall-snowmelt driven flow regime. Peak discharges occur in winter, originating from precipitation in Germany and France (Silva et al., 2004). In 1993 and 1995, floods in the Rhine basin caused significant damage in Germany, and during the 1995 flood 250000 Dutch people had to be evacuated. The highest discharge measured during these floods was $12600 \mathrm{~m}^{3} / \mathrm{s}$ at the German-Dutch border. In Northrhine-Westphalia (NRW) and The Netherlands (NL) strong dikes have been constructed to protect the land from flooding.

The yearly probability of flooding varies between about 1:200 in the south of NRW to 1:10000 in the west of NL. Just across the border in The Netherlands the safety standard is $1: 1250$. The design discharge connected to this safety standard is based on observed yearly peak discharges and is regularly reviewed. In 2001, the design discharge was adjusted from $15000 \mathrm{~m}^{3} / \mathrm{s}$ to $16000 \mathrm{~m}^{3} / \mathrm{s}$. To be able to facilitate (increasing) design discharges, both NL and NRW developed flood management policies that embrace the idea of giving back space to the river, instead of heightening dikes. Moreover, both established a set of flood management measures that should be implemented until 2015 (Landesministerium für Umwelt und Naturschutz, Landwirtschaft und Verbraucherschutz, 2006; Rijkswaterstaat, 1998). In NRW, planned measures consist of renovation and relocation of dikes and creating controlled retention areas. The Dutch measures focus on excavation of floodplains, establishment of bypasses and local relocation of dikes (cf. Silva et al., 2004).

In NL, flood protection on the large rivers is the responsibility of the national Ministry of Transport, Public Works 
and Water Management. In NRW, the Ministry of the Environment and Conservation, Agriculture and Consumer Protection is not responsible for flood protection, but influences it through financing the work done by local organizations (Deichpflichtigen). International agreements and regulations, such as the Flood Action Plan of the International Commission for the Protection of the Rhine (Internationale Kommission zum Schutz des Rheins, 1998) and the new European Flood Directive (2007/60/EC), may also influence flood management.

Since 1997, a broad range of governmental actors from NRW and NL exchange knowledge and conduct joint research in the German-Dutch Working Group on Flood Management (WGFM). In February 2007, they agreed on a new work plan for the years 2007-2012. Focus points in this plan include studying the consequences of climate change and spatial and socioeconomic changes (Provincie Gelderland et al., 2007). Climate change may increase future peak discharges of the Rhine, and social and economic changes may increase potential damage of flooding, and may decrease available space for additional retention. Therefore, additional measures may be needed to reduce flood risk in the future. This article identifies the changes that flood management stakeholders expect until 2050 and the strategies that they propose to deal with these changes.

\section{Q methodology}

To elicit stakeholder perspectives, Q methodology was used (Brown, 1980; McKeown and Thomas, 1988; Stephenson, 1953). Q methodology is intended to systematically elicit individual perspectives, and to group them into shared perspectives using quantitative factor analysis. A strength of the method is that it does not require shared perspectives, or groups of subjects that share them, to be known or hypothesized in advance (Donner, 2001). Moreover, it analyses each individual perspective as a whole, and does not aim to generate correlations between objective attributes that are abstracted from the individual (Steelman and Maguire, 1999), such as nationality, gender, age and preferred management strategy. Q sort can be used with a small, selected sample of individuals and is not intended to generalize the results to a larger population (Steelman and Maguire, 1999).

Q methodology consists of the following five steps (cf. Donner, 2001; van Exel and de Graaf, 2005; see Appendix A for a more extensive discussion of $\mathrm{Q}$ methodology):

1. Collection of all possible statements about the issue at hand (the "concourse")

2. Selection of most relevant statements (the "Q set")

3. Selection of respondents (the "P set")

4. Ranking of statements by respondents according to how much they agree with each statement ("Q sorting")

\section{Analysis and interpretation}

In the scenario study, a literature study and 23 exploratory, semi-structured interviews were conducted for developing the "concourse". All members of the WGFM, as well as some other governmental actors and NGOs, were interviewed. The statements that were collected concerned four issues that are relevant in a scenario study: 1) the current situation, 2) autonomous developments, 3) management strategies, and 4) the desired future situation. In order to improve the understandability and recognizability of the statements among flood management stakeholders, they were kept close to their original wording.

Only the most relevant statements could be included in the "Q set", in order to limit the time required to perform the sorting task. In particular, statements on which opinions were expected to diverge were included. Preliminary Q sets were discussed with several colleagues of the authors, in order to test their consistency and completeness. Finally, 46 statements were selected. The statements were translated into German and Dutch and included in an online tool, set up using free web-based software (available at http://q.sortserve.com).

In order to identify a broad variety of perspectives, more than 200 stakeholders were invited by e-mail to fill in the online Q sorting questionnaire, including policymakers, scientists and societal actors (NGOs, citizens and businesses). In total, 47 people (22\%) responded to the Q sorting questionnaire (see Table 1), with a good balance between Dutch and German respondents. More than half of the respondents work for governmental organizations - at local, regional, or national level - and about one fourth for universities. NGOs, citizens, businesses, and German scientists were relatively underrepresented.

The respondents were instructed to sort the statements from the Q set according to how much they agreed with them. They were forced to assign a fixed number of statements to each of the scoring categories, ranging from strong agreement to strong disagreement (Table 2). The fixed distribution ensures that the respondents compare the statements relatively to each other, which decreases the risk of arbitrary or biased sorting, and increases the repeatability of the sort (see Appendix A for further discussion).

Before the Q sorting, the respondents were asked for their name and affiliation. After the sorting, they were asked to explain why they agreed so strongly with the statements that they gave $\mathrm{a}+3$ score and why they disagreed so strongly with the statements that they gave a -3 score. Furthermore, they were asked to report on any technical problems, on problems with understanding the statements, and whether they had missed statements. Comments on the meaning of particular statements by German respondents resulted in a few minor reformulations.

To support the analysis of the results, the free PQMethod software was used (available at http://www.qmethod.org). 
Table 1. Groups of respondents, time of Q sorting, number addressed and number of respondents.

\begin{tabular}{|c|c|c|c|}
\hline Group of respondents & Time of Q sorting & Number Addressed & Number of Responses \\
\hline German-Dutch Working Group on Flood Management & Sep ’06 & 17 & 7 \\
\hline Other interviewees \& water management scientists & Sep '06-Feb ’07 & 30 & 13 \\
\hline Union of Dutch River Municipalities (VNR) & Sep ’06-Feb ’07 & 45 & 6 \\
\hline $\begin{array}{l}\text { Hochwassernotgemeinschaft Rhein } \\
\text { (Local governments, citizens and businesses) }\end{array}$ & Sep '06-Feb '07 & 81 & 10 \\
\hline Participants 2nd workshop, including upstream Bundesländer & Apr ’07 & 10 & 6 \\
\hline $\begin{array}{l}\text { International Commission for the Protection of the Rhine } \\
\text { (ICPR), Working Group on Flood Management + Observers }\end{array}$ & Sep '07-Oct' 07 & 30 & 5 \\
\hline
\end{tabular}

Table 2. Fixed distribution of statements over score categories.

\begin{tabular}{lccccccc}
\hline Meaning & \multicolumn{3}{c}{ Most disagree } & \multicolumn{5}{c}{ Most agree } \\
\hline Score category & -3 & -2 & -1 & 0 & 1 & 2 & 3 \\
Number of statements & 4 & 5 & 9 & 10 & 9 & 5 & 4 \\
\hline
\end{tabular}

This software uses factor analysis to explain as much of the variance among the individual Q sorts as possible in terms of a few scoring patterns called factors. "Factor" is thus the more technical term for "shared perspective" and both terms are used interchangeably in the remainder of this paper. PQMethod maximized the total variance between the factors using Varimax rotation, and calculated Pearson's correlation coefficients (for forced distribution data) between individual Q sorts and the resulting factors: the factor loadings. Subsequently, the analyst selected which individual Q sorts would define each factor. Q sorts were selected, if they had a statistically significant (higher than 0.38 , with $p<0.01$; for formula, see van Exel and de Graaf, 2005) and clean loading on that factor (exceeding the loading on other factors with at least 0.1). Next, PQMethod calculated ultimate factor scores for each statement. Such a score is the weighed average score of the respondents defining that factor (individual Q sorts with high factor loading get a bigger relative weight). Furthermore, PQMethod identified a total of five consensus statements, for which the scores did not significantly differ between any of the factors, and for each factor about twenty contention statements, for which the factor scores significantly differed from those of other factors.

The analyst did not have to identify the factors: PQMethod did that. However, the analyst had to decide on the number of factors to use. After iteratively analyzing different numbers of factors, the analyst finally chose to continue the analysis with three factors. With three factors, each factor explained more of the total variance than each single Q sort (the Eigenvalue was larger than 1; Donner, 2001). Moreover, each factor was determined by more than five $\mathrm{Q}$ sorts and more than

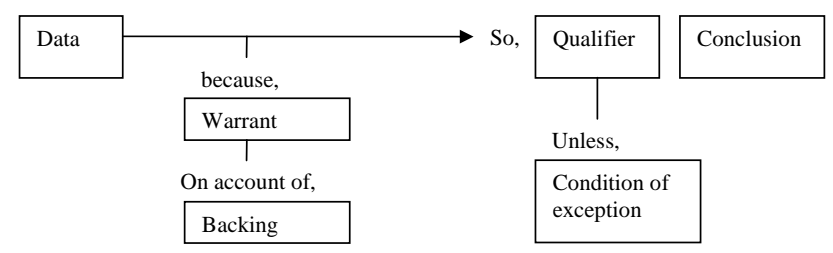

Fig. 2. Structure of an argument (Toulmin, 1958).

ten statements significantly distinguished each factor from the others. And most importantly, with three factors it was still possible for the analyst to recognize the internal logic of each factor.

To identify the internal logic of each factor, the analyst combined Q methodology with argumentation theory (Toulmin, 1958). This theory analyzes arguments in terms of 1) claims or conclusions, 2) data supporting this claim, 3) warrants linking the data with the claim, and 4) qualifiers, such as "probably" or "certainly", and 5) conditions of exception accompanying the claim. A warrant can be supported by a backing, which can be a complete argument in itself (see Fig. 2). Within a policy context, the claim concerns the measures to take, the warrants concern the perceived problems and goals and the effectiveness and efficiency of measures, and the backings concern the underlying political or ideological values (cf. Fischer, 1995; Hoppe and Peterse, 1998).

\section{Results}

The Q sorting revealed a common basis of agreement, as well as three distinct shared perspectives or factors. The three factors explain $43 \%$ of the total variance between all 47 individual Q sorts, and are defined by 36 individual Q sorts. Three $\mathrm{Q}$ sorts did not have a significant loading on any of the factors, and eight $\mathrm{Q}$ sorts did not have a clean loading. In other words, the individual perspectives of three respondents did not have much in common with the perspectives of the others, and for eight respondents it was hard to tell with whom 
Table 3. Number of respondents that define each factor per category $(\mathrm{GOV}=$ Government, $\mathrm{LOC}=\mathrm{Local}$, REG $=$ Regional, NAT $=$ National, $\mathrm{DE}=$ Germany and NL $=$ The Netherlands).

\begin{tabular}{lcccccccc}
\hline & \multicolumn{3}{c}{ Affiliation } & & Nationality & Total \\
\hline & Gov $_{\text {LOC }}$ & Gov $_{\text {REG }}$ & GovNAT & Science & Society & DE & NL & \\
\hline Factor A & 6 & 3 & & 6 & 3 & 9 & 9 & 18 \\
Factor B & & 2 & 8 & & 1 & 9 & 2 & 11 \\
Factor C & 1 & 1 & 4 & 1 & & 7 & 7 \\
\hline Total & 7 & 5 & 9 & 10 & 5 & 18 & 18 & 36 \\
\hline
\end{tabular}

they had most in common. Table 3 shows the composition of the groups that define each factor (share a perspective).

The statements that were sorted and the factor Q sort values are presented in Table 4. To obtain factor Q sort values, the ultimate factor scores were ordered from lowest to highest, and integer values from -3 to +3 were assigned to them, according to the same distribution that was used for the individual $Q$ sorting ( -3 for the four lowest scoring statements, -2 for the next five lowest scoring statements, etc.: see Table 2). The standard error for the ultimate factor scores indicates the probable range within which the true factor scores are likely to be located. The standard error decreases with the number of defining respondents, and is 0.20 for factor $\mathrm{A}, 0.25$ for factor B, and 0.32 for factor $\mathrm{C}$ (see for formula Brown, 1980 , p. 298). Table 4 starts with the consensus statements (with the lowest variance across factor scores), and ends with the statements on which there is most disagreement.

This section first describes the consensus statements and then presents the factors, which have been called A) "Anticipation and institutions", B) "Space for flooding" and C) "Knowledge and engineering". For each factor, the argumentation structure has been reconstructed, using only the highest and lowest scoring statements $(-3,-2,+2$ or +3$)$ for that factor. Statements related to preferred strategies have been treated as claims, and statements concerning the effectiveness and efficiency of measures, the current situation and autonomous developments as warrants (Figs. 3-5).

\subsection{Agreement between perspectives}

The five statements in the first rows of Table 4 do not significantly distinguish between any pair of shared perspectives. The shared perspectives agree that it is not very important to pay more attention to smaller floods and local issues. Furthermore, flood management should not become more decentralized and controlled by local government, but NGOs and the public should be involved more actively. Concerning flood management strategies, the opinion is shared that creating space between the river dikes is not a completely sufficient strategy for the period until 2050. In addition, socioeconomic developments in flood prone areas should be miti- gated through spatial planning and construction regulation.

\subsection{Perspective A: "Anticipation and institutions"}

A large group of respondents from different backgrounds, but with relatively many from local governments (see Table 3), share a perspective that we have named "Anticipation and institutions" (see Fig. 3). This group expects many significant autonomous developments that will increase both the probability and the potential damage of floods and that will limit the options for future measures. Although climate change will significantly increase peak discharges, discharges at the German-Dutch border will not exceed $17000 \mathrm{~m}^{3} / \mathrm{s}$ because of floods in Germany. The potential damage in flood-prone areas will increase significantly and increasing spatial pressure will lead to a decreasing range of possible measures. It is important to act quickly, and to cooperate at river basin level. Appropriate physical measures are holding back water in the basin through land use changes and local infiltration, and adjusting timing of peak flows from the main tributaries. Dike heightening is not considered effective and efficient. Most proposed measures, however, concern institutions, e.g., law, policy and organizational structures. They include transboundary harmonization of methods to determine safety standards, creating a simple governance structure and a strong river basin authority, and better integration of water and spatial planning.

\subsection{Perspective B: "Space for flooding"}

Perspective B, which we named "Space for flooding", is determined mostly by high-level (national) German governmental actors (see Table 3 ). As in perspective A, the message is that action needs to be taken fast because spatial pressure along the river is increasing (see Fig. 4). However, perspective $\mathrm{B}$ focuses on the current situation. In this perspective, the Flood Action plan of the International Commission for the Protection of the Rhine (ICPR) is seen as useful to increase the efforts of riparian countries, and informal cooperation is seen as essential for transboundary flood management. Concerning user functions, perspective $\mathrm{B}$ indicates that agriculture and economy are already valued enough and that a 
Table 4. Factor $\mathrm{Q}$ sort values, starting with the statements on which there is most agreement between factors (-3: strongly disagree with statement, +3: strongly agree with statement).

\begin{tabular}{|c|c|c|c|c|}
\hline \multirow[t]{2}{*}{ Nr. } & \multirow[t]{2}{*}{ Statements } & \multicolumn{3}{|c|}{ Factor values } \\
\hline & & A & B & $\mathrm{C}$ \\
\hline 24 & $\begin{array}{l}\text { Creating space for the river by removal of obstacles, floodplain excavation and dike relocation is a sufficient strategy for flood } \\
\text { management until } 2050 .\end{array}$ & -1 & -1 & -1 \\
\hline 36 & $\begin{array}{l}\text { Socio-economic developments in flood prone areas should not be mitigated through spatial planning and construction regula- } \\
\text { tion. }\end{array}$ & -1 & -3 & -2 \\
\hline 14 & It is important to pay more attention to smaller floods and local issues, instead of extreme floods. & -1 & 0 & -1 \\
\hline 27 & Flood management should become more decentralised and controlled by local government bodies. & -2 & -2 & -2 \\
\hline 26 & It is not useful to involve non-governmental organisations and the public more actively in flood management decision-making. & -3 & -2 & -2 \\
\hline 8 & Looking ten years ahead in the development of flood management policies is sufficient. & -3 & -1 & -3 \\
\hline 45 & In 2050 the river landscape should be open and enjoyable to live and recreate in. & 1 & 2 & 1 \\
\hline 20 & There will be large changes in the administrative structure of flood management until 2050. & 0 & -1 & -1 \\
\hline 18 & $\begin{array}{l}\text { The potential damage in the flood prone areas in Northrhine-Westphalia and The Netherlands will not significantly increase } \\
\text { until } 2050 .\end{array}$ & -2 & -1 & -1 \\
\hline 46 & It would be acceptable when in 2050 the current high safety levels could not be guaranteed anymore. & -3 & -2 & -3 \\
\hline 15 & Climate change will significantly increase peak discharges at the Lower Rhine betwe & 2 & 1 & 0 \\
\hline 35 & $\begin{array}{l}\text { Soft measures like offering compensation or options for insurance are good possibilities to cover residual potential flood } \\
\text { damage. }\end{array}$ & -1 & 0 & 0 \\
\hline 31 & $\begin{array}{l}\text { Downstream countries should search for and finance measures in upstream countries, when this provides more effective or } \\
\text { efficient solutions. }\end{array}$ & 1 & 1 & 0 \\
\hline 12 & A simple governance structure, with clear and little overlapping tasks and responsibilities, is beneficial for flood management. & 3 & 2 & 1 \\
\hline 30 & A better integration of water management and spatial planning is essential to solve future flood management problems. & 3 & 1 & 2 \\
\hline 16 & Floodings in Germany will prevent the occurrence of & 2 & 1 & 2 \\
\hline 23 & The water sector will gain in importance relatively to other sectors (e.g., agriculture, spatial planning) between now and 2050. & 1 & 0 & 1 \\
\hline 25 & In the next decades, bypasses (e.g., "green rivers") have to be realised to safely accommodate increasing peak dischar & 0 & 0 & -1 \\
\hline 32 & Existing dikes, rivers and floodplains should be better maintained. & 0 & 0 & 2 \\
\hline 2 & The ICPR Flood Action Plan is useful because it stimulates countries to put additional effort in flood management. & 0 & 2 & 1 \\
\hline 1 & The priority of flood management on the political agenda is currently too low. & 1 & -1 & 1 \\
\hline 34 & p better disaster management plans that thoroughly consider the logistics of potential evacuations. & 2 & 3 & 2 \\
\hline 7 & It is necessary to develop a clearer perspective on the desired state of "nature", e.g., clearer ecological goals. & 0 & 2 & 0 \\
\hline 33 & The Rhine countries should develop more controlled retention polders and optimise their use for the whole Rhine basin. & 1 & 0 & -1 \\
\hline 21 & $\begin{array}{l}\text { The European Union Flood Directive will significantly increase the influence of downstream countries on flood management } \\
\text { in upstream countries. }\end{array}$ & -1 & -1 & 0 \\
\hline 4 & Current safety standards in The Netherlands and Northrhine-Westphalia are adequate. & -1 & 0 & 0 \\
\hline 10 & $\begin{array}{l}\text { Because the range of possible flood management measures is decreasing due to increasing spatial pressure, it is important to } \\
\text { take action fast. }\end{array}$ & 3 & 2 & 1 \\
\hline 43 & In 2050 the Rhine should still offer plenty of opportunities to a broad range of (user) functions. & 1 & 3 & 3 \\
\hline 3 & Agriculture and other economic activities are not valued high enough in current flood management. & 0 & -2 & -1 \\
\hline 11 & It is more important that citizens and businesses feel safe than that they are aware of and prepared for possible flooding. & -2 & -3 & -3 \\
\hline 42 & In 2050 safety standards should be differentiated, based on the values to be protected in a certain area. & 1 & 0 & 3 \\
\hline 19 & Spatial pressure along the river will decrease between now and 2050, as agricultural land use decreases. & -1 & -3 & 0 \\
\hline 22 & $\begin{array}{l}\text { Improvement of computer technology and models between now and } 2050 \text { will lead to new, valuable insights in the behaviour } \\
\text { of the river system. }\end{array}$ & 0 & 1 & 3 \\
\hline 9 & The Dutch five-yearly review of the design discharge guarantees that flood prevention stays up to date in an efficient way. & -1 & 1 & -1 \\
\hline 39 & At locations where technical flood prevention measures are difficult to establish, flooding should be accepted. & -1 & 1 & 0 \\
\hline 5 & Informal cooperation is essential for success in transboundary flood management. & 0 & 3 & 1 \\
\hline 29 & $\begin{array}{l}\text { Adjusting the timing of peak flows from the main tributaries can hardly contribute to preventing peak flows on the Lower } \\
\text { Rhine. }\end{array}$ & -2 & 0 & 0 \\
\hline 40 & $\begin{array}{l}\text { A harmonised approach to determine design discharges and safety standards in The Netherlands and Germany should be } \\
\text { operational in } 2050 \text {. }\end{array}$ & 3 & 0 & 1 \\
\hline 13 & Scientific and expert knowledge are currently not well enough adopted in policy formulation and decision-making. & 0 & -1 & 2 \\
\hline 41 & In 2050 ideally a strong river basin authority has been established. & 2 & -1 & -1 \\
\hline 6 & Spatial quality is as important as safety against flooding. & 0 & 1 & -2 \\
\hline 17 & $\begin{array}{l}\text { Because the effects of climate change on peak discharges are still unclear and contradictory, it is better to wait than to take } \\
\text { action now. }\end{array}$ & -3 & -1 & 0 \\
\hline 38 & Residual flood risk should be reduced by controlled flooding (e.g., emergency flood detention areas) and compartmentalisation. & 1 & 3 & -2 \\
\hline 44 & In 2050 the dikes should have been retreated, and the river should be revitalised and meandering. & 1 & 1 & -3 \\
\hline 28 & $\begin{array}{l}\text { Holding back the water through land use changes and local infiltration upstream in the Rhine basin is useful to decrease peak } \\
\text { discharges on the Niederrhein. }\end{array}$ & 2 & -3 & 1 \\
\hline 37 & Dike heightening is an effective and efficient strategy for future flood management. & & -2 & 3 \\
\hline
\end{tabular}




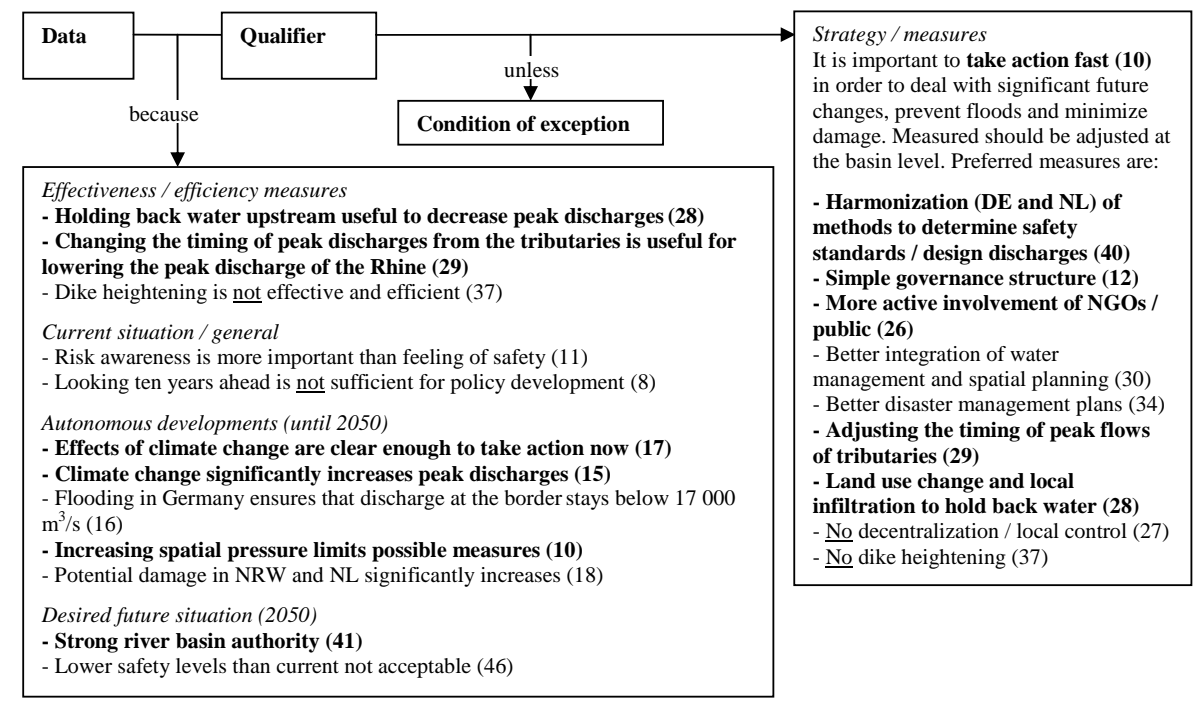

Fig. 3. Argumentative structure for factor A "Anticipation and institutions" (Bold indicates statements that significantly distinguish this factor from the other factors with $p<0.05$ ).

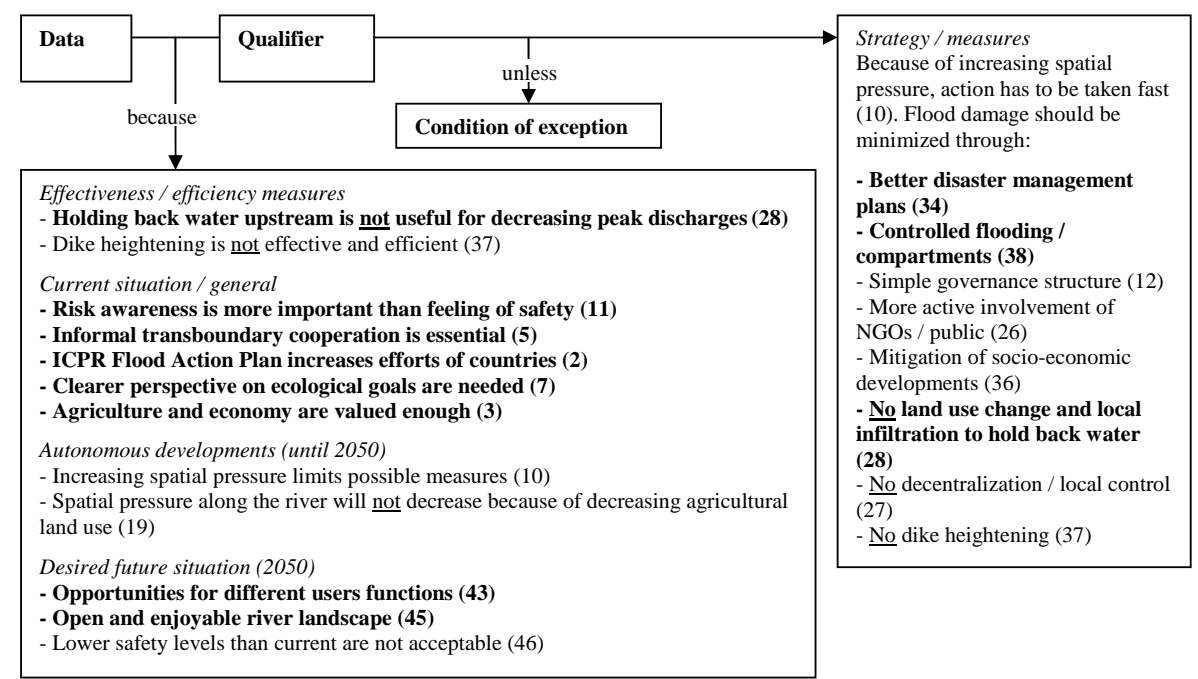

Fig. 4. Argumentative structure for factor B "Space for flooding" (Bold indicates statements that significantly distinguish this factor from the other factors with $p<0.05)$.

clearer perspective on ecological goals is needed (it is not clear whether this means that ecology should receive more or less attention). In the vision for 2050, the Rhine offers opportunities for a broad range of user functions and the river landscape is open and enjoyable to live and recreate in. The strategies concentrate on minimizing potential damage by controlled flooding and compartmentalization, and by mitigating socio-economic developments through land use planning and construction regulation. As perspective $\mathrm{A}$, this perspective favors a simple governance structure, and considers dike heightening not to be effective and efficient. In contrast

www.hydrol-earth-syst-sci.net/12/1097/2008/ to perspective $\mathrm{A}$, holding back water in the basin is seen as not useful for decreasing peak discharges of the Rhine.

\subsection{Perspective C: "Knowledge and engineering"}

Perspective C (Fig. 5), which we named "Knowledge and engineering", is fully determined by seven Dutch respondents, mostly scientist (Table 3 ). This perspective claims that expert knowledge should play a larger role in policymaking, and that a long-term perspective should be developed, aimed at establishing safety against flooding more than at improving 


\begin{tabular}{|c|c|c|c|}
\hline \multirow[t]{2}{*}{ Data } & Qualifier & & \multirow{7}{*}{$\begin{array}{l}\text { Strategy / measures } \\
\text { Policy should be based on scientific } \\
\text { knowledge. Future changes should be } \\
\text { dealt with mainly by flood } \\
\text { prevention. Good measures are: } \\
\text { - Dike heightening (37) } \\
\text { - Differentiation of safety standards } \\
\text { (42) } \\
\text { - Better integration of water } \\
\text { management and spatial planning } \\
\text { (30) } \\
\text { - Better disaster management plans } \\
\text { (34) } \\
\text { - Better maintenance (32) } \\
\text { - Mitigation of socio-economic } \\
\text { developments (36) } \\
\text { - More active involvement of NGOs / } \\
\text { public (26) } \\
\text { - No controlled flooding / } \\
\text { compartments (38) } \\
\text { - No decentralization / local control } \\
\text { (27) }\end{array}$} \\
\hline & & $\underset{\downarrow}{\substack{1 \\
\downarrow}}$ & \\
\hline & & Condition of exception & \\
\hline \multicolumn{3}{|c|}{$\begin{array}{l}\text { Effectiveness / efficiency measures } \\
\text { - Dike heightening is effective and efficient (37) }\end{array}$} & \\
\hline \multicolumn{3}{|c|}{$\begin{array}{l}\text { Current situation / general } \\
\text { - Expert knowledge is not sufficiently used in policymaking (13) } \\
\text { - Looking ten years ahead is not sufficient for policy development (8) } \\
\text { - Safety against flooding is more important than spatial quality (6) } \\
\text { - Risk awareness is more important than feeling of safety (11) }\end{array}$} & \\
\hline \multicolumn{3}{|c|}{$\begin{array}{l}\text { Autonomous developments (until 2050) } \\
\text { - Improvement of computers / models leads to new insights (22) } \\
\text { - Floodings in Germany make sure the discharge at the border stays below } 17000 \\
\mathrm{~m}^{3} / \mathrm{s}(16)\end{array}$} & \\
\hline $\begin{array}{l}\text { Desire } \\
\text { - Oppo } \\
\text { - Safet } \\
\text { - Lowe }\end{array}$ & $\begin{array}{l}\text { tion (2050) } \\
\text { lifferent users } \\
\text { differentiate } \\
\text { s than current }\end{array}$ & $\begin{array}{l}\text { ons (43) } \\
\text { d on values to protect }(42) \\
\text { t acceptable (46) }\end{array}$ & \\
\hline \multicolumn{3}{|c|}{ - Dikes not retreated to revitalise the river $(44)$} & \\
\hline
\end{tabular}

Fig. 5. Argumentative structure for factor C "Knowledge and engineering" (Bold indicates statements that significantly distinguish this factor from the other factors with $p<0.05$ ).

Table 5. Correlations between factor scores with uncertainty bounds (98\% confidence interval; See for formula Brown, 1980, p. 286).

\begin{tabular}{cccc}
\hline Factor & $\mathrm{A}$ & $\mathrm{B}$ & $\mathrm{C}$ \\
\hline $\mathrm{A}$ & 1.00 & $0.54 \pm 0.10$ & $0.46 \pm 0.11$ \\
$\mathrm{~B}$ & $0.54 \pm 0.10$ & 1.00 & $0.38 \pm 0.12$ \\
$\mathrm{C}$ & $0.46 \pm 0.11$ & $0.38 \pm 0.12$ & 1.00 \\
\hline
\end{tabular}

spatial quality. Factor $\mathrm{C}$ expects improvements in computer technology and simulation models and more insight in the behavior of the river system between now and 2050. Furthermore, it expects that the discharge at Lobith will remain below $17000 \mathrm{~m}^{3} / \mathrm{s}$ because of flooding in Germany. In the desired future situation, the Rhine offers opportunities for a broad range of user functions. It is not desired to retreat dikes and revitalize the river. The proposed measures are mostly engineering activities, such as dike heightening in combination with better maintenance of existing rivers, floodplains and dikes. In addition, damage in case of flooding should be reduced by differentiation of safety standards based on the values to be protected in each area, mitigation of socioeconomic developments, and integration of water management and spatial planning. This factor opposes the development of emergency flood detention areas to control flooding.

\section{Analysis of shared perspectives}

Although three different perspectives could be identified, there is in fact a lot of agreement. The lowest correlation that could be found between an individual Q sort and a factor or another individual Q sort was -0.22 (minimum is -1 ). Table 5 gives the correlation scores for the different factors. All pairs of factors are significantly positively correlated, with correlation coefficients above 0.38 , which indicates that the shared perspectives agree on most of the statements. The correlation coefficients do not significantly differ. The highest correlation can be found between factor A and B. This is no surprise because both emphasize the need for fast action and advocate many similar measures. The main difference between the perspectives is that A emphasizes the influence of autonomous developments, including climate change, whereas B focuses more on the current situation. Perspective $C$ has a relatively low correlation with other factors, because it focuses on other developments - knowledge - and not on the need to act quickly, and proposes a strategy that other factors oppose - dike heightening.

The main technical points on which the shared perspectives do not agree include the effects of climate change on peak discharges, the influence of new technology and new insights, and the development of spatial pressure along the river. Furthermore, the perspectives do not agree on the efficiency and effectiveness of dike heightening, holding back water in the basin, and adjusting timing of peak flows from tributaries.

The different perspectives as represented in Figs. 3-5 include claims and warrants, but no backings and data to support them and no qualifiers and conditions of exception. This is the result of the composition of the Q set. In reality, many of the claims and warrants can be related to previously performed research. An example of an influential report was the research into the transboundary effects of extreme floods on the Niederrhein (Lammersen, 2004), indicating that due to flooding in Germany the peak discharge at the GermanDutch border can currently not exceed $15500 \mathrm{~m}^{3} / \mathrm{s}$ and is not 
expected to exceed $16500 \mathrm{~m}^{3} / \mathrm{s}$ under future climate change.

The warrants in a policy context contain goals that are worthy to be promoted, which in turn depend on general values or worldviews and on specific, local interests (cf. Fischer, 1995; Sabatier, 1998). The latter were elicited indirectly since they are usually implied in the arguments and actions of the stakeholders concerned rather than applied consciously, and asking directly for values may result in unreliable artificial answers. Instead, the shared perspectives were analyzed in order to find underlying values that could explain them. In all perspectives, safety seems to be a central value that should be protected now and in the future. Moreover, all factors aim for more active involvement of NGOs and the public, but it is unclear whether public participation is seen as a means for empowerment and direct democracy, or as a means to educate the public and obtain support for management, which would be compatible with a government and science centered worldview (cf. Mostert, 2005; Webler and Tuler, 2006).

In addition to these values that all three perspectives share, some values are more specific. The main values underlying perspective A, besides safety, seem to be concern for the future and international cooperation. A central value in perspective B seems to be minimizing costs. This perspective anticipates only changes in spatial pressure, and proposes to assign emergency flood detention areas to ensure safety, which requires little government investments. Perspective C positively values economic efficiency and technology. It argues to invest in well-known, cost-efficient engineering measures and it relies on development of knowledge and technology. Furthermore, factor $\mathrm{C}$ suggests spatial differentiation of safety standards based on values to protect, which may improve efficiency of flood protection.

\section{Use of shared perspectives}

An overview of stakeholder perspectives can be used to support the management of natural resources in different ways. This section discusses how perspectives can be used, and how the perspectives presented in this article were used in the ACER-NeWater case study. First, the perspectives can be used to outline areas of consensus and conflict (cf. Steelman and Maguire, 1999). Areas of conflict may point to conflicting values and interests, to conflicting technical knowledge, or to a combination of both. In the last two cases, outlining these areas may help to set the research agenda. In the presented case, however, the agenda had already been set and $\mathrm{Q}$ sorting was used primarily to confirm the choices that had been made before.

Second, the elicitation of shared perspectives can promote reflection by the stakeholders and increase awareness of similarities and differences in each others' perspectives. The Q sorting itself already forces the respondents to think about a comprehensive set of statements. These may concern aspects that the respondent did not consider before in relation to the issue at hand, but that are relevant to other stakeholders. After analysis, the overview of shared perspective can be used to raise awareness among a broad audience. For this purpose, the analyst needs to communicate the perspectives to the intended audience. In the case study, (preliminary versions of) the results have been disseminated to different audiences at different moments in time. The results were disseminated 1) by sending a paper with the results to all respondents, 2) by presenting the results at stakeholder meetings, e.g., the second stakeholder workshop in the case study, and 3) by publishing and presenting papers (e.g., Raadgever et al., 2007, which contains some preliminary results) to address the scientific community.

Third, knowing the areas of consensus and conflict can also help facilitators to design and implement participatory activities that may lead to the resolution of conflict (cf. Focht, 2002). It helps to identify the controversial issues that should be discussed and may be sensitive. In the case study, for example, the more precautionary attitude of perspective A may conflict with the more economy-oriented attitude in perspective $\mathrm{B}$ and $\mathrm{C}$.

Finally, shared perspectives about the future can be used as input for scenario studies. In the case study, the perspectives have been compared with worldview-based scenarios from the literature. This comparison indicated that the scenarios from literature cover a larger variety of possible futures, and are more consistent and better grounded in science. Perspective-based scenarios, however, may be easier to relate to the knowledge and experience of stakeholders, and may support a feeling of ownership among stakeholders (Raadgever and Becker, 2008).

\section{Conclusions}

The main aim of this article was to identify stakeholder perspectives on future flood management in the Rhine basin. Forty-seven individual perspectives were elicited, using an online Q sorting questionnaire, and three distinct shared perspectives, as well as areas of agreement, were identified using factor analysis. The respondents largely agreed that it may be useful to mitigate socio-economic developments in flood prone areas through regulation, and to involve NGOs and the public more strongly in flood management. Moreover, they agreed that flood management should not become more decentralized. The three shared perspectives on future flood management were named: A) "Anticipation and institutions", B) "Space for flooding", and C) "Knowledge and engineering". In perspective A, climate change and economic growth will increase future flood risk, requiring active anticipation. Proposed measures have an institutional character, e.g., development of a stronger basin commission. In perspective $\mathrm{B}$, there is a need for fast action in order to deal with the increasing spatial pressure on the river area. The proposed measures are mainly aimed at mitigating damage, 
e.g., through controlled flooding and compartmentalization. In perspective $\mathrm{C}$, expert knowledge is considered very important for policy-making, and is expected to improve due to technological developments. Suitable strategies include strengthening the dikes and more differentiation of safety standards.

A secondary aim was to show how perspectives can be measured and analyzed. Q methodology proved to be an effective tool for measuring perspectives, allowing for structured elicitation of individual perspectives, and identification of shared perspectives and groups of respondents that share these perspectives. Moreover, it can gain from combinations with other tools and approaches, such as interviews and argumentation theory for reconstructing argumentation patterns. However, Q methodology is a time-intensive method for analysts and may be difficult and time-consuming for respondents. Therefore, it is most appropriate for in-depth analysis (see also Appendix A).

Another secondary aim was to discuss how elicited perspectives can be used in management of complex natural resources management issues. First, the technical aspects on which the perspectives disagree reveal relevant topics for researchers who want to do policy-relevant research. Second, the identified differences in values and interests indicate relevant, and potentially sensitive, themes for discussion and negotiation among stakeholders. Such information is useful for organizers of participatory processes. Third, perspectives can be used to increase the awareness among stakeholders of similarities and differences between their perspectives. This awareness may support the discussion of underlying data, including uncertainties, qualifiers and conditions of exception. And fourth, perspectives can be used for scenario development.

As part of the $\mathrm{PhD}$ research of the first author, it is measured whether collaboration between stakeholders leads to changes in perspectives (cf. Pelletier et al., 1999), in the presented case and in a Dutch groundwater management case. Additional empirical research is needed to develop better insight in how perspectives can be used to improve natural resource management.

\section{Appendix A}

\section{Q methodology}

Several methods can be used for identifying individual perspectives, such as interviewing (e.g., Denzin and Lincoln, 2000), cognitive mapping (e.g., Eden, 1988; Ridder et al., 2005), and card sorting (e.g., Pahl-Wostl and Hare, 2004; Rugg and McGeorge, 1997). Traditionally, these methods were used to elicit expert knowledge, but they can also be used for obtaining local and experiential knowledge (cf. Evans, 1988), values and interests. To identify major knowledge gaps and conflicts of interest, and to support presenta- tion and discussion of perspectives, it is useful to summarize differences and similarities by grouping individual perspectives. Compared to other elicitation methods, Q methodology supports the most objective and reproducible grouping of perspectives.

Q methodology, however, requires careful interpretation of sophisticated statistical results (Rugg and McGeorge, 1997). Therefore, a new $\mathrm{Q}$ analyst should do some reading in order to be introduced in the methodology. This Appendix first describes the five basic steps in a Q methodological study (cf. Donner, 2001; van Exel and de Graaf, 2005). Second, it discusses three aspects that are related to the strengths and weaknesses of the methodology: 1) the interpretations that have to be made by the analyst during the application of $\mathrm{Q}$ methodology, 2) the quality of resulting individual perspectives, and 3) the representativeness of the resulting shared perspectives.

A1 Collection of all possible statements about the issue at hand (the "concourse")

The concourse of statements can be collected by means of, for example, interviewing or studying policy documents, newspapers or scientific literature. The concourse should be broad and contain elements of the perspectives of all stakeholders. The statements should stay close to their original wording.

\section{A2 Selection of most relevant statements (the "Q set")}

The selection of the most relevant statements from the concourse is a crucial activity in Q methodology. It can be done according to a fixed structure - either imposed on the concourse (e.g., Dryzek, 1993) or emerging from it - or in a more intuitive way. When the $\mathrm{Q}$ set concerns a practical management issue, using an intuitive or bottom-up or an intuitive approach may be more useful than imposing a theoretical framework, as this allows for including as many aspects - that are relevant from a practical management point of view - as possible. The number of statements in the $\mathrm{Q}$ set usually varies between 40 and 60 , depending on the complexity of the issue at stake and on the time the respondents may be willing to spend. The Q set should be broad and clear enough to activate the tacit criteria, or underlying values, of all respondents and to give the researcher insight in them (Donner, 2001). No matter what effort is undertaken, obtaining a balanced set remains "more an art than a science" (Brown, 1980). Finally, the statement should be edited, randomly numbered, and either printed on separate cards - for face to face Q sorting interviews - or included in an online Q sorting tool.

\section{A3 Selection of respondents (the "P set")}

The $\mathrm{P}$ set should be a structured sample of relevant stakeholders who may be expected to have clear and distinct 
viewpoints. The $\mathrm{P}$ set should maximize the likelihood that all major perspectives on the issue are included (Brown, 1980). The number of respondents is usually between 20 and 40 .

\section{A4 Ranking of statements by respondents ("Q sorting”)}

After completion of the P set, the Q sorting can start. Respondents are instructed to rank the statements according to some rule or question. The statements have to be ranked into score categories representing a gliding scale, for example from strong agreement to strong disagreement. For respondents, the time for executing the Q sorting task varies between fifteen minutes and one hour, dependent on the number of statements and the way of sorting. The way of sorting can influence both quality of results and effectiveness of application. Using an online tool, instead of face-to-face Q sorting interviews, allows respondents to perform the sort at any convenient time. Furthermore, it significantly reduces the time the analyst needs to conduct the sort. Disadvantages of an online set-up are the potentially lower response rate and limited possibilities to explain respondents how to perform the task. Whether conducted online or face-to-face, it is recommended to follow up the $\mathrm{Q}$ sorting with the question why the respondent assigned certain statements to the most extreme score categories. This supports a valid and fast interpretation of factors in the last step of Q methodology (cf. Steelman and Maguire, 1999). Face-to-face interviews provide more opportunities for additional questions. There is no apparent difference, however, in reliability and validity of computerand interview-based Q sorts (van Tubergen and Olins, 1979 in van Exel and de Graaf, 2005).

In many $\mathrm{Q}$ methodological studies, the respondents are forced to distribute the statements over the score categories according to a fixed, uni-modal, and symmetric distribution (see for example Table 2). Such a fixed distribution forces respondents to carefully compare the statements relatively to each other. This is assumed to decrease the risk of arbitrary or biased sorting, for example under influence of the respondent's mood at the time of sorting, and thus to increase the repeatability of the sort. However, from the study described in this article it occurred that some respondents were dissatisfied about the time and effort required to, iteratively, put a fixed number of statements in each score category, and about the fact that their perspective could not be expressed well using the given distribution (cf. Rugg and McGeorge, 1997, who see this as a major disadvantage of Q sorting). This could be solved by allowing respondents to distribute statements over categories as they want, without prescribing the shape of the distribution (e.g., Steelman and Maguire, 1999). This has no significant consequences for the factor analysis (McKeown and Thomas, 1988). When the respondents are not at all stimulated to evaluate their agreement with one statement relatively to their agreement with another, however, accuracy of the elicited perspectives will be low. A disadvantage of many web-based tools, including the tool used in this study, is that they do not allow any deviation from the predetermined distribution.

\section{A5 Analysis and interpretation}

Software tools, such as the PQMethod software (freely available from http://www.qmethod.org), can support analysis of obtained Q sorts (individual scoring patterns) using factor analysis. Factor analysis is a statistical data reduction technique used to explain as much of the variability among the observed Q sorts as possible in terms of a few unobserved scoring patterns, called factors. PQMethod calculates the eight factors with the highest explanatory value, and presents the ratio of the total variance between the $\mathrm{Q}$ sorts that each factor explains. The next step for the analyst is to choose the number of factors to be included in the analysis. These factors should at least explain more of the total variance than a single Q sort (in other words, the Eigenvalue should be larger than 1; Donner, 2001). Other criteria for the choice of the number of factors are the number of $\mathrm{Q}$ sorts determining each factor, and the number and internal logic of the statements that distinguish each factor form the other factors. These criteria can only be evaluated through initial analysis of the content of the factors, which consequently has to be repeated several times for sets of different numbers of factors.

After the analyst has chosen the appropriate number of factors for further analysis, PQMethod can clarify the structure of the factors by objectively maximizing variance between each of them using Varimax rotation. Alternatively, more subjective manual factor rotation can be used when the analyst aims to confirm a certain prior idea or theory (van Exel and de Graaf, 2005). After factor rotation, PQMethod calculates the correlation between individual $\mathrm{Q}$ sorts and factors, the factor loadings. Subsequently the analyst selected which individual Q sorts will define each factor. Usually, Q sorts are selected, when they have a statistically significant and clean loading on that factor. Then, ultimate factor scores are calculated, as an average of the defining Q sorts, weighted by their factor loadings. PQMethod produces several outputs that are useful for further analysis. Essential are the contention statements, for which factor scores differ significantly between at least two factors, and consensus statements, for which factor scores do not differ significantly between any of the factors. The logic of each factor should be interpreted by the analyst and each factor should be named. Finally, and maybe most importantly, the results have to be disseminated and processed in a proper way.

\section{A6 Interpretations by the analyst}

A strength of Q methodology is that it leaves relatively little space for the general political and ideological values of the researcher to exert influence on the outcomes. Still, the results of a Q methodological study depend on the selection 
of statements to include in the Q set, including formulation and translation, and the selection of stakeholders to include in the $\mathrm{P}$ set. Ideally, all important stakeholder groups and all different perspectives should be reflected, but there are practical limitations as to their size. Inadvertently, important stakeholders and perspectives may be missed, and, moreover, who decides on what is "important"? The same is true for the researcher's choice of the number of factors to use, the reconstruction of the argumentation in each factor, and the name given to each factor.

\section{A7 Quality of individual perspectives}

In order to get an impression of the validity of the elicited individual perspectives, individual $\mathrm{Q}$ sorts that were obtained in the case study have been compared to individual perspectives that were obtained using interviews and cognitive mapping. Individual cognitive maps were initially developed by the main author of this article, based on individual interview results, in preparation of the first ACER-NeWater workshop. During the workshop, participants elaborated the perspectives captured in the cognitive maps. In sum, eight respondents to the Q sort were also interviewed, and four of them participated in the cognitive mapping exercise. For each individual, it was assessed how many of the statements that received the scores $-3,-2,+2$ or +3 in the $\mathrm{Q}$ sort were also reflected in the interview and cognitive map. On average, $30 \%$ of these statements were reflected in the interviews and $40 \%$ in the cognitive maps, and about $50 \%$ were not reflected in either of them. Thus, Q sorting identifies much more aspects as relevant than the aspects respondents come up with themselves. This points to the fact that Q methodology is not only an elicitation technique, but it forces respondents to reflect on a broad range of aspects. The remaining 10-20\% of the most relevant Q sort statements seemed to be contradicted in the interviews and cognitive maps. Possible explanations for this are that individual perspectives changed between different elicitation moments, or that the analyst interpreted statements in a different way than the interviewee. In addition, the interviews and cognitive maps included some claims, and in particular some detailed explanations, that were not evident in the $\mathrm{Q}$ sorts.

\section{A8 Representativeness of shared perspectives}

Representativeness of the set of shared perspectives can be determined by the variety of measured individual perspectives, and the way in which these perspectives are aggregated. A major advantage of Q methodology is that it takes only a small sample of respondents to produce statically reliable results (Brown, 1980). By aggregating a large number of individual perspectives in a small number of shared perspectives, communication, comprehension, and comparison become easier.
Acknowledgements. The authors would like to thank all respondents for their cooperation and emphasize that this article does not represent any official position, and involves interpretation by the authors. Furthermore the authors are grateful for the help of Gert Becker (VU IVM) and others that contributed to setting up the Q sort. The research for this article was executed under the projects NeWater (Contract no 511179, 6th EU framework program) and ACER. The authors would like to thank the European Commission and the Water Resources Centre Delft for the financial support received.

Edited by: F. Pappenberger

\section{References}

Brown, S. R.: Political subjectivity: Application of q methodology in political science, Yale University Press, New Haven, 1980.

Denzin, N. K. and Lincoln, Y. S.: Handbook of qualitative research, 2nd Ed., Sage, Thousand Oaks, 2000.

Dewulf, A., Craps, M., and Dercon, G.: How issues get framed and reframed when different communities meet: A multi-level analysis of a collaborative soil conservation initiative in the Ecuadorian Andes, J. Community Appl. Soc., 14, 177-192, 2004.

Donner, J. C.: Using q-sorts in participatory processes: An introduction to the methodology, Social analysis: Selected tools and techniques, Social Development Papers No. 36, The World Bank, Social Development Department, Washington DC, 2001.

Doyle, J. K. and Ford, D. N.: Mental models concepts for system dynamics research, Syst. Dynam. Rev., 14, 3-29, 1998.

Dryzek, J. S.: Reconstructive democratic theory, The American Political Science Review, 87, 48-60, 1993.

Eden, C.: Cognitive mapping: A review, Eur. J. Oper. Res., 36, 113,1988

Evans, J. S. T.: The knowledge elicitation problem - a psychological perspective, Behav. Inform. Technol., 7, 111-130, 1988.

Fischer, F.: Evaluating public policy, Nelson-Hall, Chicago, 1995.

Focht, W.: Assessment and management of policy conflict in the Illinois River watershed in Oklahoma: An application of $\mathrm{q}$ methodology, Int. J. Public Admin., 25, 1311-1349, 2002.

Gabr, H. S.: Perception of urban waterfront aesthetics along the Nile in Cairo, Egypt, Coast. Manage., 32, 155-171, 2004.

Hoppe, R. and Peterse, A.: Bouwstenen voor argumentatieve beleidsanalyse, Elsevier Bedrijfsinformatie, 's-Gravenhage, 1998.

Internationale Kommission zum Schutz des Rheins: Aktionsplan Hochwasser, Rotterdam, 1998.

Kolkman, M. J., Kok, M., and van der Veen, A.: Mental model mapping as a new tool to analyse the use of information in decisionmaking in integrated water management, Phys. Chem. Earth, 30, 317-332, 2005.

Lammersen, R.: Grensoverschrijdende effecten van extreem hoogwater op de Niederrhein, Rijkswaterstaat RIZA, Landesumweltamt NRW, Bundesanstalt für Gewässerkunde, Düsseldorf, 2004.

Landesministerium für Umwelt und Naturschutz, Landwirtschaft und Verbraucherschutz: Bericht an den Ausschuss für Umwelt und Naturschutz, Landwirstschaft und Verbraucherschutz des Landes Nordrhein-Westfalen über das Hochwasserschutzkonzept für den Zeitraum bis 2015, Düsseldorf, 2006. 
McKeown, B. and Thomas, D.: Q methodology, Sage university papers. Quantitative applications in the social sciences 66, Sage, Newbury Park, 1988.

Mostert, E.: Public participation and ideology, in: Partizipation, Öffentlichkeitsbeteiligung, Nachhaltigkeit; Perspektiven der politischen Ökonomie, edited by: Feindt, P. H., and Newig, J., Metropolis Verlag, Marburg, 163-179, 2005.

Pahl-Wostl, C. and Hare, M.: Processes of social learning in integrated resources management, J. Community Appl. Soc., 14, 193-206, 2004.

Pelletier, D., Kraak, V., McCullum, C., Uusitalo, U., and Rich, R.: The shaping of collective values through deliberative democracy: An empirical study from New York's North Country, Policy Sci., 32, 103-131, 1999.

Provincie Gelderland, Ministerie Verkeer en Waterstaat, and Landesministerium für Umwelt und Naturschutz, Landwirtschaft und Verbraucherschutz: Gemeinsame Erklärung für die Zusammenarbeit im nachhaltigen Hochwasserschutz für den Zeitraum 2007 bis 2012, 2007.

Raadgever, G. T., Becker, G., and Mostert, E.: Perspectives on future flood management: Discovering patterns of thinking, in: Changes in water resources systems: Methodologies to maintain water security and ensure integrated management, edited by: Van de Giesen, N. C., Jun, X., Rosjberg, D., and Fukushima, Y., IAHS Press, Wallingford, 186-191, 2007.

Raadgever, G. T., and Becker, G.: Exploring future flood management: A comparison of scenarios from literature and stakeholder perspectives, in: Managing Flood Risk, Reliability and Vulnerability (Proceedings of the 4th International Symposium on Flood Defence), edited by: Simonovic, S. P., Bourget, P. G., and Blanchard, S. F., ICLR, Toronto, 95, 1-9, 2008.

Ridder, D., Mostert, E., Wolters, H. A., Cernesson, F., Echavarren, J. M., Enserink, B., Kranz, N., Maestu, J., Maurel, P., Otter, H., Patel, M., Schlussmeier, B., Tabará, D., and Taillieu, T.: Learning together to manage together - Improving participation in water management, Druckhaus Bergmann, Osnabrück, 2005.
Rijkswaterstaat: Flood Defences Act, Policy Creating space for the river, Rijkswaterstaat Road and Hydraulic Engineering division, Delft, 1998.

Rugg, G. and McGeorge, P.: The sorting techniques: A tutorial paper on card sorts, picture sorts and item sorts, Expert Syst., 14, 80-93, 1997.

Sabatier, P. A.: The advocacy coalition framework: Revisions and relevance for Europe, J. Eur. Public Policy, 5, 98-130, 1998.

Silva, W., Dijkman, J. P. M., and Loucks, D. P.: Flood management options for the Netherlands, International Journal of River Basin Management, 2, 101-112, 2004.

Steelman, T. A. and Maguire, L. A.: Understanding participant perspectives: Q-methodology in national forest management, J. Policy Anal. Manag., 18, 361-388, 1999.

Stephenson, W.: The study of behavior: Q-technique and its methodology, University of Chicago Press, Chicago, 1953.

Thompson, M., Ellis, R., and Wildavsky, A.: Cultural theory, Political cultures, Westview Press, Boulder, 1990.

Toulmin, S. E.: The uses of argument, Cambridge University Press, Cambridge, 1958.

van Asselt, M. B. A., Middelkoop, H., van 't Klooster, S. A., van Deursen, W. P. A., Haasnoot, M., Kwadijk, J. C. J., Buiteveld, H., Können, G. P., Rotmans, J., van Gemert, N., and Valkering, P.: Integrated water management strategies for the Rhine and Meuse basins in a changing environment, RIVM, Bilthoven, 2001.

van Exel, N. J. A. and de Graaf, G.: Q methodology: A sneak preview, 2005.

van Tubergen, G. N. and Olins, R. A.: Mail vs personal interview administration for q sorts: A comparative study, Operant Subjectivity, 2, 51-59, 1979.

Webler, T. and Tuler, S.: Four perspectives on public participation process in environmental assessment and decision making: Combined results from 10 case studies, Policy Stud. J., 34, 699-722, 2006. 